\title{
ORDEM PATRIARCAL DE GÊNERO, MEDIAÇÃO E SERVIÇO SOCIAL
}

\section{Taynara Fitz Patriarcha* e Sandra Lourenço de Andrade Fortuna}

\section{Resumo}

O presente trabalho é um ensaio teórico, parte de uma pesquisa intitulada «A ordem patriarcal de gênero no processo de formação profissional dos cursos de Serviço Social das Universidades públicas do norte do Paraná». Neste artigo, buscou-se versar a respeito das determinações da ordem patriarcal de gênero na trajetória do Serviço Social brasileiro e traduzir sua importância enquanto categoria de mediação. Por tratar-se de uma profissão majoritariamente composta por mulheres numa sociabilidade pautada na ordem patriarcal de gênero entrelaçada com os antagonismos de raça/etnia e das contradições de classe na ordem do capital, as particularidades postas no movimento do real devem ser analisadas à luz da apreensão crítica desta profissão.

Palavras-chave: Ordem patriarcal de gênero, capitalismo, racismo, mediação, serviço social.

\section{Abstract}

\section{Patriarchal Gender Order, Mediation and Social Work}

The present paper is a theoretical essay, part of a research entitled «The Patriarchal order of gender in the professional training process of Social Work courses at public universities in the north of Paraná». In this article, we deal with the patriarchal order of gender determinations in the trajectory of Brazilian Social Work, as well as to translate its importance as a mediation category. Since it is a profession dominated by women, in a sociability based on the patriarchal order of gender, interlaced with the antagonisms of race/ethnicity and class contradictions in the order of capital, the particularities placed in the movement of the real must be analyzed in the light of a critical apprehension of this profession.

Keywords: Patriarchal order of gender, capitalism, racism, mediation, social work.

\section{Résumé}

Ordre patriarcale de genre, médiation et travail social

Le présent ouvrage est un essai théorique, qui fait partie d'une recherche intitulée «L'Ordre patriarcal de genre dans le processus de formation professionnelle des cours de

Centro de Estudos Sociais Aplicados, Departamento de Serviço Social, Programa de pós-graduação em Serviço Social e Política Social da Universidade Estadual de Londrina (UEL), Brasil. Endereço postal: Rodovia Celso Garcia Cid, Pr 445 Km 380 - Cx. Postal 10.011 - Campus Universitário, Londrina - PR, 86057-970, Londrina-Paraná, Brasil.

Endereço eletrónico: taynarafitz@gmail.com

** Centro de Estudos Sociais Aplicados, Departamento de Serviço Social, Programa de pós-graduação em Serviço Social e Política Social da Universidade Estadual de Londrina (UEL), Brasil. Endereço eletrónico: sandralourencofortuna@gmail.com 
Travail Social des universités publiques au nord du Paraná». Dans cet article, nous traitons des déterminations de l'ordre patriarcal du genre dans la trajectoire du Travail Social brésilien, bien comme à traduire son importance comme catégorie de médiation. Comme cette profession est dominée par des femmes dans une sociabilité basée sur l'ordre patriarcale du genre, entrelacé par les antagonismes de race/ethnicité et les contradictions de classe dans l'ordre du capital, les particularités placées dans le mouvement du réel doivent être analysées à la lumière de l'appréhension critique de cette profession.

Mots clés: Ordre patriarcale de genre, capitalisme, racisme, médiation, travail social.

\section{Ordem patriarcal de gênero e serviço social}

As determinações da ordem patriarcal de gênero inseridas na realidade do Serviço Social brasileiro têm a sua marca desde a gênese da profissão, no princípio do século XX.

Nesse período, o Brasil foi marcado pela transição do capitalismo concorrencial ao monopolista, momento este no qual o capital experimentava, desde o final do século XIX, profundas modificações na sua dinâmica, trazendo consigo o acirramento da contradição entre capital e trabalho.

A organização do capitalismo monopolista tem por finalidade obter «o acréscimo dos lucros capitalistas através do controle dos mercados» (J. P. Netto 2011a, 20). Dessa maneira, o capital, no estágio dos monopólios, conduziu ao seu ápice a socialização da produção e a apropriação cada vez mais privada da riqueza socialmente produzida. Esse processo favoreceu o adensamento do exército industrial de reserva, acirrando cada vez mais a luta de classes.

O momento tornou a «questão social» ${ }^{1}$ evidente, impedindo a sociedade burguesa de ignorar sua existência e demandando intervenções sobre as suas expressões. Dessa forma, a «questão social» é compreendida como:

as expressões do processo de formação e desenvolvimento da classe operária e de seu ingresso no cenário político da sociedade, exigindo seu reconhecimento como classe por parte do empresariado e do Estado. É a manifestação, no cotidiano da vida social, da contradição entre o proletariado e a burguesia, a qual passa a exigir outros tipos de intervenção, mais além da caridade e repressão (Iamamoto e Carvalho 2012, 84).

Para esta finalidade, surgiram diversas organizações assistenciais vinculadas à Igreja Católica e de setores dominantes da sociedade, em sua maioria constituí-

\footnotetext{
É necessária a utilização das aspas referente à expressão «questão social» tendo em vista a sua apropriação por diversas vertentes de pensamento, a destacar a corrente conservadora. O conservadorismo converte a «questão social» em ação moralizadora, dessa forma, há uma naturalização de suas expressões (J. P. Netto 2011a). Neste trabalho compreendemos a necessidade de situar a «questão social» na complexa estrutura histórica determinada pela contradição de classes imanente ao capital.
} 
das por mulheres. O Estado, por sua vez, tratava o assunto com o uso da repressão policial, sendo a coerção uma resposta recorrente frente ao adensamento da pobreza.

A predominância de mulheres nas obras assistenciais era justificada na compreensão de uma suposta «vocação natural» delas para tarefas de caráter caritativo e educativo.

Não somente é justificável a ação feminina social como ainda é indispensável [...]. Não tem a mulher, na sociedade, a missão de educar? Imaginem a restauração da família sem a cooperação da mulher: a remodelação da mentalidade, de hábitos e de costumes que irão depois influir na economia e nas leis do país, tem de ser, toda ela, trabalho da mulher, em qualquer classe da sociedade (Iamamoto e Carvalho 2012, 183).

Com a emergência do capitalismo monopolista e a organização da classe trabalhadora avançando em meados da década de 1930, a caridade e a coerção não eram suficientes para suprimir as manifestações do pauperismo e conter os movimentos reivindicatórios dos trabalhadores. Dessa forma, o Estado brasileiro viu a necessidade de intervenção na «questão social» por meio da regulamentação das relações de trabalho, bem como outras regulamentações referentes à proteção social, culminando na emergência das políticas sociais no país. Essa estratégia tornou-se viável à medida que servia aos interesses burgueses, buscando atenuar os conflitos sociais originados da luta de classes e exercer o controle sobre a classe trabalhadora.

Nesse sentido, se o governo Vargas enfrentou também com a polícia os componentes mais radicalizados do movimento operário nascente, em especial após 1935, ele soube combinar essa atitude com uma forte iniciativa política: regulamentação das relações de trabalho no país, buscando transformar a luta de classes em colaboração de classes, e o impulso à construção do Estado social, em sintonia com os processos internacionais, mas com nossas mediações internas particulares (Behring e Boschetti 2011, 106).

O surgimento da política social no Brasil acarretou uma crescente demanda por profissionais do Serviço Social formados pela primeira Escola de Serviço Social, implantada em São Paulo em 1936. ${ }^{2}$

Além das requisições do capital monopolista por uma profissão que atuasse no enfrentamento às expressões da «questão social», a implantação da primeira escola de Serviço Social no Brasil também estava inserida no esforço da Igreja Católica para reestabelecer o bloco católico. Para Iamamoto e Carvalho (2012), a necessidade de rearticulação das bases católicas foi uma reação da Igreja à sua perda de hegemonia nos diversos espaços da sociedade. A perda dos privilégios da Igreja Católica ocorreu com o fim do Império e a implantação da primeira Constituição republicana do Brasil em 1891, determinando a laicização do Estado. Um dos reflexos dessa rearticulação católica foi a criação do Centro de Estudos e Ação Social de São Paulo (CEAS), em 1932, que deu suporte para a criação da primeira escola de Serviço Social no Brasil. 
As primeiras escolas de Serviço Social ofereciam uma formação profissional alicerçada na Doutrina Social da Igreja e também na filosofia neotomista. A Doutrina Social da Igreja tem por base as encíclicas papais, sendo duas dessas a Rerum Novarum e Quadragésimo Anno. Tais documentos interpretam a «questão social» enquanto fruto de um problema moral da sociedade. Sendo assim, essa perspectiva acredita na coesão de classes e na humanização do capital, considera ser possível «atenuar a desigualdade social, sem questionar a viabilidade do capitalismo» (Guedes 2000, 63). Já a filosofia neotomista compreende que «a existência do homem não se esgota na esfera material, mas obedece a uma finalidade espiritual. A existência material inscreve-se, assim, no horizonte do aperfeiçoamento para o infinito» (Guedes 2000, 20).

Para o exercício de suas funções, era necessário que as/os assistentes sociais daquele período incorporassem princípios da formação moral cristã, além de serem necessárias as seguintes características:

um sólido preparo técnico [que] alie o desinteresse pessoal, uma grande capacidade de devotamento e sentimento de amor ao próximo; deve ser realmente solicitado pela situação penosa de seus irmãos, pelas injustiças sociais, pela ignorância, pela miséria, e a esta solicitação devem corresponder as qualidades pessoais de inteligência e vontade (Iamamoto e Carvalho 2012, 233-234).

Essas características foram historicamente atribuídas pela ordem patriarcal de gênero ${ }^{3}$ à suposta natureza feminina. Não foi por acaso, portanto, que o Serviço Social brasileiro emergiu como profissão majoritariamente constituída por mulheres. Assim, a profissão foi caracterizada pelo exercício do cuidado, como tantas outras profissões ${ }^{4}$ marcadas por esse processo de feminização.

O Serviço Social adequou-se ao leque de oportunidades de carreira permitido às mulheres, desde o fim do século 19, uma alternativa à inserção no mercado de trabalho. Essa inserção foi permitida pela sociedade à medida que as mulheres passaram a exercer trabalhos extensivos aos já exercidos por elas no mundo privado (Cisne 2015, 54).

As determinações da ordem patriarcal de gênero na origem do Serviço Social se deram em razão de seu quadro profissional ser composto majoritariamente por mulheres, o que lhe conferiu desprestígio social enquanto profissão inserida na

Optámos neste trabalho por trabalhar com a categoria «ordem patriarcal de gênero», fazendo, assim, «o uso simultâneo dos conceitos de gênero e de patriarcado, já que um é genérico e o outro específico dos últimos seis ou sete milênios, o primeiro cobrindo toda a história e o segundo qualificando o primeiro» (Saffioti 2004, 132).

4 O Serviço Social não é a única profissão com essa característica, porém, neste trabalho, nos dedicaremos apenas à análise dessa profissão. 
divisão sexual do trabalho. ${ }^{5}$ Mas também pelas práticas das primeiras assistentes sociais junto à classe trabalhadora, principalmente aquelas em relação às mulheres, que eram reproduções explícitas da manutenção do ideário patriarcal e conservador.

A divisão sexual do trabalho é fomentada, reproduzida, apropriada e muito bem utilizada para atender aos interesses da classe dominante. Para atender a tais interesses, as(os) assistentes sociais atuavam junto à família, mais especificamente sobre a mulher, para atingir os operários, uma vez que é por intermédio dela que se encontrava o caminho necessário para o alcance da «preservação da ordem moral e social» (Cisne 2015, 58).

A partir da década de 1940, o Serviço Social, buscando atualização teórico-metodológica, aproxima-se da teoria social positivista. ${ }^{6}$ Sendo assim, a profissão se compromete com o aperfeiçoamento das técnicas e instrumentos de trabalho, entretanto não se desvincula da postura humanista e cristã. Essa estrutura também foi chamada de «arranjo teórico-doutrinário», o que, conforme Iamamoto, "permite que a profissão mantenha seu caráter missionário, atualizando as marcas de origem e atendendo, concomitantemente, às exigências de tecnificação que lhe impõe a modernização da sociedade e do Estado» (Iamamoto 2002, 28).

A influência da matriz teórico-positivista na formação das/os assistentes sociais daquele momento não colidiu com a perspectiva conservadora existente na profissão sobre as atribuições socialmente construídas a respeito das mulheres na sociedade. Pelo contrário, reforçava a suposta «missão» das mulheres na preservação da moralidade cristã na sociedade.

Os positivistas elevaram as mulheres por meio do que se poderia considerar como sendo a transfiguração do culto da Virgem. [...] Para os positivistas, a mulher constituía a base da família, a qual era pedra fundamental da sociedade. A mulher formava o núcleo moral da sociedade, vivendo sobretudo através dos sentimentos [...]. Dela dependia a regeneração da sociedade (Hahner 1978 apud Ary 2000, 73).

Com o atributo do positivismo, também se justificava a refuncionalização da ordem patriarcal de gênero, reforçando determinismos biológicos, em benefício da conservação da ordem social vigente.

Nesse sentido, essas assistentes sociais canalizavam para as mulheres a responsabilidade com a reprodução social e todo o «equilíbrio» social. Logo, pode-se concluir que

Sobre a divisão sexual do trabalho, ver Souza-Lobo (1991); Kergoat (2009); Cisne (2015).

Sobre o positivismo, Yazbek aponta que «este horizonte analítico aborda as relações sociais dos indivíduos no plano de suas vivências imediatas, como fatos, como dados, que se apresentam em sua objetividade e imediaticidade» $(2009,147)$. 
a incorporação por parte das pioneiras das qualidades naturais atribuídas às mulheres facilitou as respostas que foram exigidas na época à profissão para o controle da «questão social» (Cisne 2015, 64).

A crítica ao Serviço Social tradicional ocorreu a partir da década de 1960 com o Movimento de Reconceituação. ${ }^{7}$ A Reconceituação foi concebida na conjuntura histórica das particularidades da América Latina, marcada naquela ocasião pela ascensão das Ditaduras Militares.

No Brasil, com o golpe militar em 1964, o movimento profissional sofreu com os Atos Institucionais que legitimavam as ações políticas e coercitivas dos militares no poder. Diante desse contexto, o Serviço Social, impossibilitado de questionar-se politicamente, questionou-se teórico-metodologicamente.

José Paulo Netto (2011b) compreendeu o Movimento de Reconceituação de acordo com três perspectivas: Modernizadora, Reatualização do Conservadorismo, Intenção de Ruptura. É importante considerar que foram vertentes que disputavam a hegemonia nos debates profissionais daquele período, entretanto não significou a formação de uma categoria profissional homogênea.

A Reconceituação visava romper com o Serviço Social tradicional, mas legitimou-se numa dinâmica de continuidade das práticas conservadoras do estágio anterior da profissão. Dessa maneira, o Serviço Social brasileiro, na sua trajetória, recebeu influências tanto do conservadorismo denominado «romântico», como do chamado conservadorismo «moderno».

O conservadorismo romântico é o ideário que explicitava resistência ao racionalismo e à transformação, principalmente no que se refere aos princípios da revolução francesa, e aos postulados iluministas (Lacerda e Guedes 2006). Assim, os românticos compreendiam que a aproximação do homem com a razão significava seu afastamento de Deus.

O conservadorismo romântico situa-se nas origens da profissão, tomando por base a matriz filosófica neotomista de origem franco-belga.

Segundo a filosofia neotomista, o homem, para realizar-se na esfera a-temporal, não pode prescindir da sociedade. Mas qual sociedade pode servir a este fim? Os primeiros assistentes sociais, a partir desta questão, se propunham a trabalhar com vistas a uma sociedade ideal em que o bem comum pudesse ser alcançado, na via do conservadorismo romântico que tem o passado medieval como modelo de sociedade a ser restaurado. É a partir destes parâmetros que os assistentes sociais, como salienta Mancini, «agiam com os olhos no futuro», como numa cruzada evangélica, procurando atenuar os problemas sociais que distanciavam a sociedade do bem comum. Contudo, estes profissionais deveriam ter respostas concretas às mazelas sociais [...]. Como conciliar estas respostas com a construção de uma sociedade ideal? A Igreja Católica apontava um caminho: a conciliação entre as classes sociais (Guedes 2000, 16-17).

Sobre o Movimento de Reconceituação, ver J. P. Netto (2011b). 
O conservadorismo «moderno» foi caracterizado pela vinculação ao positivismo durkheimiano, metamorfoseou-se de conservadorismo antiburguês para conservadorismo antiproletário. A função dessa fase do ideário conservador era a manutenção da ordem burguesa, permitindo reformas dentro dessa ordem contra a ameaça revolucionário-socialista (L. E. Netto 2011).

Foi nas perspectivas do Movimento de Reconceituação, denominadas de Modernizadora e Reatualização do Conservadorismo, que esse ideário, na sua forma transformada, esteve presente na profissão.

Quanto a esse reflexo na perspectiva Modernizadora, o Serviço Social se alinhou ao direcionamento desenvolvimentista que o país adotava naquele período, que privilegiava a proposta de atuação no Desenvolvimento de Comunidade e compreendia que era «necessária a remoção de obstáculos e solução dos problemas [da comunidade] para elevação das massas subdesenvolvidas» (Guedes 2005, 138).

Este discurso aponta a filiação do Serviço Social à ideologia desenvolvimentista e demonstra o entendimento de que é possível «elevar as massas», promovendo um capitalismo harmônico e humanizado, sendo que este ideal de sociedade é, ainda, resquício da perspectiva do Bem Comum idealizado por Maritain, mas agora influenciado pelo funcionalismo (Lacerda e Guedes 2006).

Na Reatualização do Conservadorismo, a profissão tem suas bases teórico-metodológicas voltadas para a fenomenologia, que compreendia a realidade no campo microssocial, «não se questionando as estruturas sociais, centrando a prática profissional no indivíduo e, mais, na subjetividade do indivíduo, permanecendo no pensamento conservador» (Lacerda e Guedes 2006).

$\mathrm{Na}$ intenção de ruptura, as/os assistentes sociais aproximaram-se da teoria social de Marx. Foi essa perspectiva que, de fato, possibilitou o questionamento do referencial teórico conservador presente na profissão. Contudo, essa imersão no marxismo, a princípio, «valeu-se de manuais de divulgação de qualidade muito discutível ou de versões deformadas pela contaminação neopositivista» (J. P. Netto $2011 b, 148)$. No entanto, ressaltamos que a conjuntura repressiva, devido aos regimes militares, não favorecia a disseminação de leituras de direcionamento crítico. Dessa maneira, o acesso a esses materiais era ainda mais restrito.

A inspiração marxiana no Serviço Social foi possível, efetivamente, apenas nos anos 1980, centralizando o debate profissional no rompimento com o imediatismo e na apreensão crítica das «mediações que compõem o ser social e as relações sociais nas quais esse se insere» (Cisne 2015, 68). Nessa concepção, também se afirmou o comprometimento do Serviço Social com a classe trabalhadora. Esse referencial ofereceu uma perspectiva crítica sobre a formação da sociedade capitalista, direcionando o Código de Ética, a formação profissional e as regulamentações desta profissão.

Diante dessa nova perspectiva, surgiu o projeto ético-político do Serviço Social. Um projeto profissional que sistematiza a direção ético-política adotada 
hegemonicamente na profissão, sustentada por denso arcabouço teórico, ${ }^{8}$ além do aspecto legal, a partir da Lei 8662/1993 - Lei de Regulamentação da Profissão - e o Código de Ética de 1993 (CFESS 1993).

Uma de suas orientações se caracteriza pela «construção de uma nova ordem social, sem exploração/dominação de classe, etnia e gênero» (J. P. Netto 2009, 155). Nessa passagem, sobretudo, reafirma-se a perspectiva de transformação social e aponta-se o compromisso da profissão com uma direção pautada na oposição ao Sistema de Dominação/Exploração vigente.

A dimensão axiológica aqui apontada contribui para a apreensão da realidade para além das aparências, captando as contradições e mediações postas no movimento do real. Dessa forma, é possível, de fato, conhecer a realidade e estabelecer ações cotidianas concretas no caminho apontado pelo referido Projeto, ou seja, a indicação de um caminho que contribua no processo de superação desse sistema de exploração e dominação. Assim, é imprescindível referir:

Se a imagem social predominante da profissão é indissociável de certos estereótipos socialmente construídos sobre a mulher na visão mais tradicional e conservadora de sua inserção na sociedade, o processo de renovação do Serviço Social é também tributário da luta pela emancipação das mulheres na sociedade brasileira (Iamamoto 1998, 104-105).

Os estudos sobre gênero passaram a ser debatidos na profissão no final da década de 1980 e meados da década de 1990, quando o Serviço Social se engajou nas lutas transversais à de classe.

Em 1990, surge na academia a categoria gênero consolidando os «estudos de gênero» em substituição a «estudos feministas» ou «da condição feminina». Aproximando-se dos movimentos feministas, a partir de 1990, o Serviço Social passa a aderir às lutas das chamadas minorias, inserindo-se nas questões relacionadas à violência contra mulheres, discriminação étnica, racial e cultural, homofobia e outras (Lisboa 2010, 71).

Devido à aproximação das/os assistentes sociais daquele momento aos estudos dessa temática, a perspectiva de gênero foi apreendida pela categoria profissional nas Diretrizes Curriculares de 1996, ainda que de forma incipiente.

Na proposta de 1996, são contemplados três núcleos de fundamentação que se inter-relacionam: Fundamentos teórico-metodológicos da vida social; Fundamentos da particularidade da formação sócio-histórica da sociedade brasileira; Fundamentos do trabalho profissional.

Sobre o Projeto Ético-Político do Serviço Social brasileiro, ver Iamamoto (1998) e J. P. Netto (2009). 
É importante salientar que o primeiro núcleo, responsável pelo tratamento do ser social enquanto totalidade histórica, analisa os componentes fundamentais da vida social, que serão particularizados nos dois outros núcleos de fundamentação da formação sócio-histórica da sociedade brasileira e do trabalho profissional. Portanto, a formação profissional constitui-se de uma totalidade de conhecimentos que estão expressos nestes três núcleos, contextualizados historicamente e manifestos em suas particularidades (ABEPSS 1996, 8).

A perspectiva de gênero foi inserida no núcleo de Fundamentação da Formação Sócio-Histórica da Sociedade Brasileira. Apesar de os núcleos serem interdependentes e não hierárquicos, buscando uma análise integrada da realidade, é necessário que a temática perpasse pelos três núcleos de fundamentação. Portanto, a temática de gênero, na proposta de 1996, apresenta-se de forma incipiente nesse processo.

As diretrizes curriculares passaram por adaptações no modelo definido pela SESU/MEC no ano de 1999. Nessa proposta, a temática de gênero apresenta-se de forma complementar e isolada do restante das disciplinas, limitando-se apenas ao tópico de Classes e Movimentos Sociais (Lourenço 2001).

Compreendemos que a materialização das determinações da ordem patriarcal de gênero sempre influenciou substancialmente a trajetória do Serviço Social, mesmo que não discutidas ou percebidas, a princípio, por meio de uma perspectiva crítica. Para tanto, é necessária a sua compreensão enquanto categoria de mediação.

\section{Ordem patriarcal de gênero: uma mediação necessária para o serviço social}

Para a construção do conhecimento, são necessárias sucessivas aproximações com a realidade. Dessa forma, à luz do método dialético de Marx, abordaremos a importância das determinações da ordem patriarcal de gênero no Serviço Social enquanto uma das mediações necessárias para a compreensão das relações sociais. Para tanto, faremos uma aproximação com a categoria mediação tendo em vista a apreensão de alguns de seus elementos constitutivos.

A mediação pode ser definida como «a categoria central da articulação entre as partes de uma totalidade complexa, e é responsável pela possibilidade da passagem entre o imediato e o mediato» (Pontes 2015, 120). Assim, podemos referir que as mediações, por meio das aproximações sucessivas com o real, possibilitam uma superação da imediaticidade.

Este ingente processo de aproximações sucessivas torna-se um imperativo para o conhecimento dialético, justamente porque, no plano da imediaticidade, os fatos, os objetos, as coisas aparecem como seres acabados; sua gênese, sua constituição, enquanto complexo total, e as próprias mediações, ficam veladas pelo traço de positividade que o plano empírico impõe à representação do sujeito (Pontes 2016, 95). 
Assim, as mediações se configuram no plano da totalidade, compreendendo-a enquanto constituição do real. Contudo, a totalidade não representa a soma das partes, mas a composição de um grande complexo constituído por outros complexos. Dessa forma, «toda parte é também aqui um todo; o 'elemento' é sempre um complexo com propriedades concretas, qualitativamente específicas, um complexo de forças e relações diversas que agem em conjunto» (Lukács 1979, 40). Na relação desses complexos, temos a dimensão da universalidade, particularidade e singularidade.

A singularidade projeta-se no plano do cotidiano. Apresenta-se na aparência dos fenômenos e nas suas manifestações imediatas, todavia, é despida a priori de determinações históricas. Segundo Pontes, «na singularidade, as mediações, as determinações, enfim, a própria legalidade social estão inteiramente ocultas. [...] É exatamente porque a singularidade corresponde à dimensão da imediaticidade que o sujeito cognoscente apreende as categorias sociais como formas autônomas de ser» $(2016,97)$.

O caráter imediato da singularidade não a torna menos relevante nesse processo, considerando que é nessa dimensão que se estabelecem as aproximações iniciais para o conhecimento da realidade. Portanto, «a singularidade é essencial para a reconstrução do real (insuprimível como tal e parte da totalidade social), mas insuficiente por se apresentar sempre imediatamente» (Sant'ana e Silva 2013, 188).

O processo de alcance da essência invariavelmente ocorre mediatiazado pela aparência, pelo fenômeno, ou seja, sempre o sujeito parte dos fatos - que na forma fenomênica é uma abstração -, desocultando a essência através da superação da positividade dos fatos, negando-os para agarrar, através de múltiplas mediações, a totalidade concreta que, em última análise, se constitui na própria essência das coisas (Pontes 2016, 94).

Nesse sentido, a singularidade se realiza na sua relação com a universalidade, sendo esta uma dimensão regida pelas determinações das leis tendenciais da sociedade, que não se apresenta de forma aparente aos sujeitos. A particularidade também compõe essa relação, sendo que é possível entendê-la como o campo de mediações responsável por ser o canal de passagem entre os complexos da totalidade. Em síntese, «o reino da particularidade é o reino das mediações, das conexões explicativas realmente existentes e mentalmente reconstruídas pela razão ontológica» (Sant'ana e Silva 2013, 189). Embora sejam realizadas caracterizações individuais de cada dimensão, elas são meramente reflexivas, sendo esta separação inexistente nos processos sociais.

Pensar o movimento do real em sua totalidade não é destituí-lo de seus complexos particulares, ao contrário, pressupõe analisá-los por meio do parâmetro da totalidade, considerando as mediações necessárias para a compreensão e a aproximação do real. Dessa maneira, a categoria mediação apresenta-se enquanto com- 
ponente medular da dialética marxiana, responsável pela apreensão da complexidade da totalidade.

Essa perspectiva teórico-metodológica no Serviço Social brasileiro toma corpo a partir de seu processo de Reconceituação, especificamente em meados da década de 1980, período em que a profissão buscou aporte teórico na tradição marxista para a reformulação de sua perspectiva frente às expressões da «questão social» fruto da contradição capital-trabalho. Dessa forma, podemos afirmar que a categoria mediação teve papel substancial para a construção dos caminhos desta profissão.

O debate acerca da categoria de mediação no Serviço Social coincide com a necessidade de avançar a análise teórico-metodológica para que se qualificasse, no sentido de iluminar as novas questões e demandas emergentes no seio da profissão, desafiando os intelectuais da profissão a tal esforço (Pontes 2015, 122).

O Serviço Social brasileiro, portanto, a partir do referencial teórico marxista, propõe-se a apreender e atuar frente à realidade, que se apresenta contraditoriamente, numa perspectiva crítica, embora as condições objetivas de trabalho sejam adversas.

O Serviço Social é uma profissão que tem características singulares. Ela não atua sobre uma única necessidade humana (tal qual o dentista, o médico, o pedagogo...) nem tampouco se destina a todos os homens de uma sociedade, sem distinção de renda ou classe. Sua especificidade está no fato de atuar sobre todas as necessidades humanas de uma dada classe social, ou seja, aquela formada pelos grupos subalternos, pauperizados ou excluídos dos bens, serviços e riquezas dessa mesma sociedade. É por isso que os profissionais de Serviço Social atuam basicamente na trama das relações de conquista e apropriação de serviços e poder pela população excluída e dominada (Carvalho e Netto 2000, 52).

Para a análise dessa realidade complexa, é necessária a apreensão de ao menos três mediações centrais, embora não excluam as discussões de outros elementos. Para tanto, referimo-nos às mediações constitutivas do Sistema de Dominação/Exploração, que é composto pelo capitalismo, ordem patriarcal de gênero e racismo.

O importante é analisar estas contradições na condição de fundidas ou enoveladas ou enlaçadas em um nó. Não se trata da figura do nó górdio ou apertado, mas do nó frouxo, deixando mobilidade para cada uma de suas componentes. Não que cada uma destas contradições atue livre e isoladamente. No nó, elas passam a apresentar uma dinâmica especial, própria do nó. Ou seja, a dinâmica de cada uma condicionase à nova realidade, presidida por uma lógica contraditória. De acordo com as circunstâncias históricas, cada uma das contradições integrantes do nó adquire relevos 
distintos. E esta motilidade é importante reter, a fim de não se tomar nada como fixo (Saffioti 2004, 125).

Nesse sentido, é possível compreender que são contradições que se estabelecem de forma consubstancial e coextensivas. ${ }^{9}$

[A consubstancialidade] é o entrecruzamento dinâmico e complexo do conjunto de relações sociais, cada uma imprimindo sua marca nas outras, ajustando-se as outras e construindo-se de maneira recíproca. [...] Quanto à coextensividade, ela aponta para o dinamismo das relações sociais. O conceito procura dar conta do fato de que elas se produzem mutuamente (Kergoat 2010, 100).

Segundo Saffioti (2004), gênero em si não revela hierarquização, posto que trata de relações sociais entre homens-mulheres, homens-homens e mulheres-mulheres, e necessita estar vinculado à categoria patriarcado para determinar o vetor dominação-exploração (Lourenço, 2008). Portanto, é necessário colocar em evidência o adversário: a ordem patriarcal de gênero. Analisar a realidade exclusivamente por meio da dimensão de gênero significa camuflar o poder que a ordem possui.

O patriarcado refere-se a milênios da história mais próxima, nos quais se implantou uma hierarquia entre homens e mulheres, com primazia masculina. Tratar esta realidade em termos exclusivamente do conceito de gênero distrai a atenção do poder do patriarca, em especial como homem/marido, «neutralizando» a exploração-dominação masculina (Saffioti 2004, 136).

As determinações do capitalismo também estão intrinsecamente vinculadas ao patriarcado, visto que o modo de produção vigente, além de manter as relações de dominação/exploração das mulheres, previstas pela ordem patriarcal de gênero, também as intensificam, de forma a potencializar esse vetor, marginalizando-as em todas as classes sociais, principalmente nas camadas mais pauperizadas.

Nesse sentido, o capitalismo apropria-se do trabalho das mulheres em todas as esferas da sociedade. Assim, para expandir a extração de mais-valia, o capital refuncionaliza seu modo de exploração das mulheres, as quais desempenham uma jornada intensiva e extensiva de trabalho, dentro e fora da esfera privada. Portanto, a sociedade não tem apenas uma divisão social do trabalho, mas também uma divisão sexual do trabalho, sem as quais a lógica desse modo de produção estaria comprometida.

\footnotetext{
Utilizaremos os conceitos de «consubstancialidade» e «coextensividade» propostos por Kergoat (2010), tendo em vista a sua aproximação à metáfora do «nó», cunhado por Saffioti (2004), entre as três bases hierárquicas que determinam a sociedade.
} 
Sem o trabalho doméstico não remunerado, o Estado capitalista teria que arcar, por exemplo, com restaurantes, lavanderias e escolas públicas em tempo integral em grande escala, de modo a atender à massa da classe trabalhadora. Outra opção seria aumentar significativamente o salário mínimo, de tal forma que um trabalhador pudesse pagar por alguns serviços necessários à reprodução da sua força de trabalho. Ambas as alternativas implicariam em um ônus significativo que afetaria diretamente os lucros do capital (Cisne 2015, 124).

O racismo é outro eixo constitutivo do Sistema de Dominação/Exploração. Portanto, é necessária a compreensão das particularidades das dimensões raciais e étnicas desse processo.

De modo geral, contudo, a supremacia masculina perpassa todas as classes sociais, estando também presente no campo da discriminação racial. Ainda que a supremacia dos ricos e brancos torne mais complexa a percepção da dominação das mulheres pelos homens, não se pode negar que a última colocada na «ordem das bicadas»é uma mulher. Na sociedade brasileira, esta última posição é ocupada por mulheres negras e pobres (Saffioti 1987, 16).

Nessa perspectiva, a apreensão das mediações postas no movimento do real se faz a partir das bases hierárquicas que constituem o Sistema de Dominação-Exploração pautado na produção e reprodução mútua entre a ordem patriarcal de gênero, racismo, e as determinações da sociedade capitalista.

A contribuição sobre a ordem patriarcal de gênero enquanto mediação para o Serviço Social compreender e intervir nas diversas expressões da «questão social» é fundamental, desde que situada na dinâmica do Sistema de Dominação/Exploração, não apenas admitindo a existência das dimensões de gênero, classe e raça/ etnia, mas partindo da dinâmica consubstancial e coextensiva entre as bases hierárquicas que dominam e exploram os sujeitos.

\section{Considerações finais}

No presente ensaio, discutiu-se a ordem patriarcal de gênero enquanto categoria que compõe as mediações necessárias para a captação das múltiplas determinações do movimento do real, possibilitando uma perspectiva indissociável com as dimensões de raça/etnia e classe.

Foi a partir do movimento de Reconceituação brasileiro, precisamente na perspectiva de «intenção de ruptura», que se observou a aproximação do Serviço Social com as obras de Marx, além das/os autoras/es da tradição marxista. Dessa maneira, é na incorporação da dialética marxiana que o Serviço Social se apropria da categoria «mediação» para as sucessivas aproximações com a realidade. Portanto, compreende-se que o conhecimento de tais mediações, entre elas a ordem 
patriarcal de gênero, são fundamentais para uma formação e um exercício profissional crítico, comprometido com um projeto profissional que não se coloca apenas no campo teórico da compreensão da realidade, mas também na dimensão interventiva.

Neste sentido, é preciso que os profissionais articulem o conhecimento socialmente produzido e perquiram o movimento do real permanentemente, buscando apreender as manifestações particulares do universal, numa perspectiva de totalidade, numa relação imanentemente constituída entre teoria e prática, haja vista que,

a recorrência que os profissionais fazem às elaborações teóricas engendram-se, fundamentalmente, de duas determinações: da busca por saberes que tenham pertinência com a sua prática, melhor ainda, da oportunidade que as teorias portam de responder às situações com as quais os agentes se defrontam no seu cotidiano profissional e que sejam compatíveis com a visão de homem e mundo do profissional; da possibilidade de retornarem esse conhecimento à vida cotidiana, agora enriquecida pela apreensão das múltiplas determinações que a constituem, no sentido de objetivá-lo em ações, reunidas num conjunto de habilidades específicas, reconhecidas socialmente. [...] Se é no cotidiano profissional [...] que a sua instrumentalidade se materializa, desse mesmo cotidiano emergem mediações que lhe requisitam níveis de racionalidade mais elevados (Guerra 1995, 180-181).

As/os profissionais que não se debruçam sobre a realidade e apenas reiteram as suas ações podem não ser capazes de superar as regularidades da vida cotidiana como: o mimetismo, a padronização, as analogias e a repetição (Guerra 1995).

Enquanto sujeitos do processo, devem se apropriar dessas regularidades enquanto possibilidades para a elaboração teórica, o que se realiza na medida em que se colocam como inquietantes críticos da realidade e da vida social e repletos dessa disposição inquisidora permanente, proponham ações concretas, buscando estratégias de enfrentamento das condições objetivas com os outras/os profissionais e sujeitos do processo, tornando-se capazes de criar formas de resistência coletivas.

Evidentemente, não cabe a algumas categorias profissionais a transformação dessa realidade, que só pode ser concretizada mediante o movimento coletivo, todavia é possível que as profissões caminhem nessa direção, sem uma visão messiânica, mas sustentadas numa perspectiva crítica, a partir da apreensão das mediações postas no movimento do real (Lourenço 2008).

\section{Referências bibliográficas}

ABEPSS - Associação Brasileira de Ensino de Serviço Social. 1996. Diretrizes gerais para o curso de Serviço Social. Disponível no endereço http://www.cressrs.org.br/docs/Lei_ de_Diretrizes_Curriculares.pdf [Consultado em 5 de março de 2017]. 
Ary, Zaíra. 2000. Masculino e feminino no imaginário católico: da ação católica à teologia da libertação. São Paulo: Annablume; Fortaleza: Secult.

Behring, Elaine Rossetti, e Ivanete Boschetti. 2011. Política Social - fundamentos e história. 9. ed. São Paulo: Cortez.

Carvalho, Maria do Carmo B., e José Paulo Netto. 2000. Cotidiano: conhecimento e crítica. 5 . $^{\text {a }}$ ed. São Paulo: Cortez.

CFESS - Conselho Federal de Serviço Social. 1993. Código de Ética profissional do Assistente Social. Brasília: CFESS. Disponível no endereço http://www.cfess.org.br/arquivos/ CEP_CFESS-SITE.pdf [Consultado em 12 de maio de 2017].

Cisne, Mirla. 2015. Gênero, divisão sexual do trabalho e Serviço Social. 2. ${ }^{a}$ ed. São Paulo: Outras Expressões.

Guedes, Olegna de Souza. 2000. Implicações da concepção neotomista de homem na gênese no Serviço Social brasileiro - 1930/1940. Dissertação de Mestrado em Serviço Social, Pontifícia Universidade Católica de São Paulo.

Guedes, Olegna de Souza. 2005. Interpretação do Humanismo no Serviço Social Brasileiro. Tese de Doutorado em Serviço Social, Pontifícia Universidade Católica de São Paulo.

Guerra, Yolanda. 1995. A instrumentalidade do serviço social. São Paulo: Cortez.

Iamamoto, Marilda V. 1998. O Serviço Social na contemporaneidade: trabalho e formação profissional. São Paulo: Cortez.

Iamamoto, Marilda V. 2002. Renovação e conservadorismo no Serviço Social: ensaios críticos. 6. ed. São Paulo: Cortez.

Iamamoto, Marilda V., e Raul de Carvalho. 2012. Relações sociais e Serviço Social no Brasil: esboço de uma interpretação histórico-metodológica. 36. ${ }^{a}$ ed. São Paulo: Cortez.

Kergoat, Danièle. 2009. «Divisão sexual do trabalho e relações sociais de sexo». In Dicionário crítico do feminismo, editado por Helena Hirata et al., 67-75. São Paulo: Unesp.

Kergoat, Danièle. 2010. «Dinâmica e consubstancialidade das relações sociais». Novos Estudos 86: 93-103. DOI: https://doi.org/10.1590/S0101-33002010000100005

Lacerda, Lélica Elis P., e Olegna de Souza Guedes. 2006. «Do conservadorismo à moral conservadora no Serviço Social brasileiro». Serviço Social em Revista 8 (2). Disponível em http://www.uel.br/revistas/ssrevista/c-v8n2_lelica.htm

Lisboa, Teresa Kleba. 2010. «Gênero, feminismo e Serviço Social: encontros e desencontros ao longo da história da profissão». Katálysis 13 (1): 66-75. DOI: https://doi.org/10.1590/ S1414-49802010000100008

Lourenço, Sandra. 2001. Gênero: sua expressão no ensino do Serviço Social. Dissertação de Mestrado em Serviço Social, Pontifícia Universidade Católica de São Paulo.

Lourenço, Sandra. 2008. Violência conjugal: materialização das ações profissionais na área da saúde. Tese de Doutorado em Serviço Social, Universidade Estadual Paulista de Franca.

Lukács, György. 1979. Ontologia do ser social: os princípios ontológicos fundamentais de Marx. São Paulo: Editora Ciências Humanas.

Netto, José Paulo. 2009. «A construção do projeto ético-político do Serviço Social». In Serviço Social e saúde: formação e trabalho profissional, editado por Ana Elizabete Mota et al., 141160. São Paulo: Cortez.

Netto, José Paulo. 2011a. Capitalismo monopolista e Serviço Social. 8. a ed. São Paulo: Cortez.

Netto, José Paulo. 2011b. Ditadura e Serviço Social: uma análise do Serviço Social no Brasil pós-64. 16. ${ }^{\mathrm{a}}$ ed. São Paulo: Cortez.

Netto, Leila Escorsim. 2011. O conservadorismo clássico: elementos de caracterização e crítica. São Paulo: Cortez.

Pontes, Reinaldo. 2015. «A categoria mediação no Serviço Social». In Dicionário crítico de Serviço Social, editado por Sarita Amaro, 117-143. Rio de Janeiro: Editora Autografia. 
Pontes, Reinaldo. 2016. Mediação e Serviço Social: um estudo preliminar sobre a categoria teórica e sua apropriação pelo Serviço Social. 8. ${ }^{\text {a }}$ ed. São Paulo: Cortez.

Saffioti, Heleieth Iara B. 1987. O poder do macho. São Paulo: Moderna.

Saffioti, Heleieth Iara B. 2004. Gênero, patriarcado, violência. São Paulo: Fundação Perseu Abramo.

Sant'ana, Raquel Santos, e José Fernando S. da Silva. 2013. «O método na teoria social de Marx: e o Serviço Social?». Temporalis 13 (25): 181-203.

Souza-Lobo, Elisabeth. 1991. A classe operária tem dois sexos: trabalho, dominação e resistência. São Paulo: Editora Brasiliense.

Yazbek, Maria Carmelita. 2009. «Fundamentos Históricos e Teórico-metodológicos do Serviço Social». In Serviço Social: Direitos Sociais e Competências Profissionais, editado por CFESS/ABEPSS, 143-164.

Taynara Fitz Patriarcha. Estudante de Mestrado do Programa de Mestrado/Doutorado em Serviço Social e Política Social; Departamento de Serviço Social; Universidade Estadual de Londrina.

Endereço eletrónico: taynarafitz@gmail.com

Sandra Lourenço de Andrade Fortuna. Professora Associada do Programa de Mestrado/Doutorado em Serviço Social e Política Social; Departamento de Serviço Social; Universidade Estadual de Londrina/UEL.

Endereço eletrónico: sandralourencofortuna@gmail.com

Artigo recebido a 10 de outubro de 2017 e aceite para publicação a 12 de janeiro de 2018. 